“ (C) 2018 IEEE. Personal use of this material is permitted. Permission from IEEE must be obtained for all other uses, in any current or future media, including

reprinting/republishing this material for advertising or promotional purposes, creating new collective works, for resale or redistribution to servers or lists, or reuse of any copyrighted component of this work in other works." 


\title{
Pattern-Reconfigurable, Flexible, Wideband, Directive, Electrically Small Near-Field Resonant Parasitic Antenna
}

\author{
Ming-Chun Tang, Senior Member, IEEE, Boya Zhou, Student Member, IEEE, Yunlu Duan, \\ Xiaoming Chen, Student Member, IEEE, Richard W. Ziolkowski, Fellow, IEEE
}

\begin{abstract}
A pattern-reconfigurable, flexible, wideband, directive, electrically small near-field resonant parasitic (NFRP) antenna is presented. The antenna consists of a pair of Egyptian axe dipole (EAD) near-field resonant parasitic (NFRP) elements, together with a pair of shaped metallic strips that act as the driven element and are fed by a coaxial cable. These NFRP and driven elements are designed to achieve compactness. Two pairs of $p$-i-n (PIN) diodes are integrated into the driven element to enable the pattern-reconfigurability. The antenna has two switchable directive end-fire states, each pointed in direct opposition to the other. Examples of the evolution of the antenna are used to illustrate its operating principles. A prototype of the optimized design operating in a frequency range centered at $1.8 \mathrm{GHz}$ was fabricated and measured. The simulated and experimental results are in good agreement. The antenna exhibits a wide, $\sim 13.1 \%$ impedance bandwidth and a $\sim 4.42 \mathrm{dBi}$ peak realized gain in both pattern-reconfigurable states while maintaining its electrically small size: $k a \sim 0.94$. The flexibility of this antenna is demonstrated under different bending conditions by mounting it on cylinders with several different radii and the results confirm that its performance characteristics are maintained under all of them.
\end{abstract}

Index Terms - Electrically small antennas, end-fire radiation, flexible, near-field resonant parasitic antennas, pattern reconfigurability, wideband.

\section{INTRODUCTION}

$\mathrm{W}$ ith the continuing advances in integrated circuit (IC) technology, radio frequency (RF) front-ends are making

Manuscript received on Dec. 17, 2017; and revised on Feb. 09, 2018...

This work was supported in part by the National Natural Science Foundation of China contract number 61471072, in part by the Funding of the Innovative Leading Talents in Science and Technology of Chongqing contract number CSTCCXLJRC201705, in part by the Fundamental Research Fund for the Central Universities contract numbers 106112017CDJZRPY0003, in part by Funding of the Young Backbone Teachers in Colleges and Universities of Chongqing contract number 0307001104102, the Open Fund of the State Key Laboratory of Integrated Services Networks contract number ISN16-03, and in part by the Australian Research Council grant number DP160102219.

M. -C. Tang, B. Zhou, Y. Duan, and X. Chen are with the Key Laboratory of Dependable Service Computing in Cyber Physical Society Ministry of Education, College of Communication Engineering, Chongqing University, Chongqing 400044, China and also with the State Key Laboratory of Integrated Services Networks, Xidian University, Xi'an 710071, China (E-mail: tangmingchun@cqu.edu.cn);

R. W. Ziolkowski is with the University of Technology Sydney, Global Big Data Technologies Centre, Ultimo NSW 2007, Australia, and the Department of Electrical and Computer Engineering, University of Arizona, Tucson, AZ 85721, USA (E-mail: Richard.Ziolkowski@uts. edu.au). significant strides towards becoming smaller, smarter, and lighter weight. Consumer demands for higher performance wireless platforms have necessitated the associated developments of intelligent antenna systems that are electrically small in size, light weight, and adaptable to the electromagnetic and physical environments in which they operate. Reconfigurable antenna technologies have drawn increasing attention to address these needs. While providing multi-functionality in a single package, they offer significant performance advantages including the mitigation of polarization mismatch and noise issues, the prevention of electronic jamming, and the facilitation of beam forming and energy savings. Thus, reconfigurable antennas have become a major candidate for intelligent system designs.

One application is the need to simply change the main-beam direction, either forwards or backwards, for intelligent transportation systems (ITS) [1-4]. In this scenario pattern-reconfigurable antennas would facilitate two kinds of communication links. One is message communications between vehicles and access points (APs), and the other is vehicle-to-vehicle (V2V) communications between two vehicles. In both links, the main-beam of a pattern-reconfigurable antenna on a vehicle would be towards its front when the APs or other vehicles are in front of it. The antenna pattern could then be intelligently switched to the back direction when they are behind it.

Pattern-reconfigurability can be realized in real time by introducing electrically controlled devices into the antenna system. These include, for instance, installing varactors or $\mathrm{p}-\mathrm{i}-\mathrm{n}$ (PIN) diodes into its radiator elements $[5,6]$ or its feed network [7]. These elements act to reshape the antenna topology or to modify its operating mechanisms. Many types of pattern-reconfigurable antennas have been developed in recent years. These include monopole-loop antennas [8], dielectric resonator antennas [9-10], artificial structure-based antennas [11-12], parasitic loop antennas [13], closely packed array antennas [14-15], microstrip stacked array antennas [16-17], circular cavity antennas [18], parasitic layer-based antennas [19] and Yagi antennas [20-21], just to name a few. On the other hand, there have been few electrically small designs reported and their bandwidths are a real practical concern. For example, while three kinds of electrically small pattern-reconfigurable antennas were introduced in [22-24], their operational bandwidths are limited (fractional bandwidth at most $2.73 \%$ ).

Furthermore, to cope with complex physical operating environments, the flexibility of any reconfigurable antenna also 
needs to be taken into account [25]. For example, to satisfy the mechanical requirements associated with fast-moving mobile platforms, their antennas must be conformal to the surface on which they are located in order to satisfy critical aerodynamic performance criteria [26]. Consequently, it is also highly desirable to realize flexible, electrically small antennas that maintain their radiation performance while also being suitable for such physical constraints.

In this paper, a pattern-reconfigurable, flexible, wideband, directive, electrically small, near-field resonant parasitic (NFRP) antenna is presented. Two examples of the evolution of this design are introduced in Section II to illustrate its operating principles in a comprehensive manner. One explains the modification of the NFRP Egyptian axe dipole (EAD) system $[27,28]$ to achieve a further reduction in its electrically small size while maintaining its radiation performance. The second reveals the physical mechanisms leading to its wideband and directive operation. The optimized design is introduced in Section III. A prototype antenna of this design was fabricated and tested. As described in Section IV, the measured and simulated results are in good agreement. The experimental validation of the flexibility of the optimized is demonstrated in Section V.

This electrically small, flexible, pattern-reconfigurable antenna is the first reported that, to the best of our knowledge, is wideband and conformal. Its $k a=0.94$, where $a$ is the radius of the smallest sphere that completely encloses the entire antenna system, $f_{0}$ is the center frequency in its operational band, and $k$ $=2 \pi / \lambda_{0}=2 \pi f_{0} / \mathrm{c}$ is the corresponding free space wave number. Its $-10 \mathrm{~dB}$ impedance bandwidth is wide, $\sim 13.1 \%$. The antenna has two switchable end-fire states, each in direct opposition to the other, that are controlled simply with two pairs of PIN diodes. It exhibits stable radiation performance characteristics in all of the tested bending conditions. The measured peak realized gain, radiation efficiency, and front-to-back ratio are $\sim 4.42 \mathrm{dBi}, \sim 70.4 \%$, and $\sim 13.42 \mathrm{~dB}$, respectively.

We note that all the metallic elements in the antenna designs reported in this paper were chosen to be copper with its known material parameters: $\varepsilon_{r}=1.0, \mu_{r}=0.999991$ and bulk conductivity $\sigma=5.8 \times 10^{7} \mathrm{~S} / \mathrm{m}$. For ease of fabrication and measurement, the prototype was designed to operate around 1.8 $\mathrm{GHz}$. All the numerical simulations and their optimizations were performed using the frequency domain ANSYS/ANSOFT high frequency structure simulator, version 13 [29].

\section{DESIGN PRINCIPLES}

Two important modifications of the EAD NFPR elements facilitated the unique final design. Each is initially considered separately to explain the design principles in a comprehensive manner.

\section{A. Modified EAD NFRP element}

As is well-known, the length of a traditional electric dipole antenna is approximately a half wavelength [30]. As an alternative, NFRP elements are placed in the near field of an electrically small center-fed dipole to achieve similar performance while achieving a significant electrical size reduction [31].

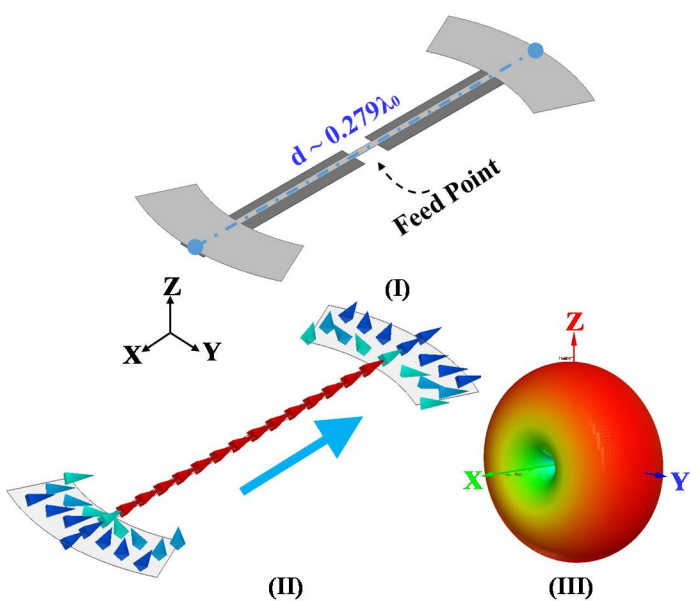

(a)

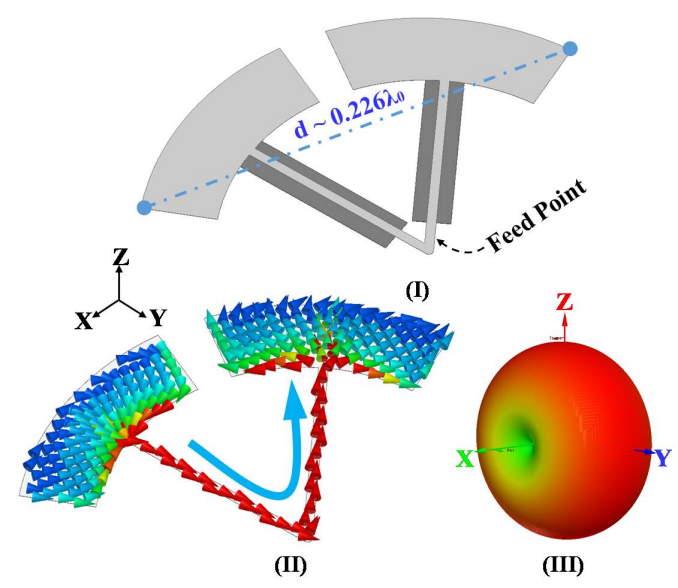

(b)

Fig. 1 Electrically small EAD NFRP elements. (a) Planar, unmodified configuration. (b) Bent, modified configuration. (I) Geometry. (II) Surface current density distribution. (III) 3-D directivity pattern.

Fig.1 illustrates the modification of the EAD NFRP element and its exciting dipole. First, a typical straight EAD NFRP element is placed above a center-fed dipole. The electrical size is $k a \sim 0.875$. As expected, this electrically small antenna exhibits high radiation efficiency $(96 \%)$ and nearly complete impedance matching. The antenna configuration together with the surface current density distribution on the top surface of the EAD NFRP element and the resulting 3-D directivity pattern at its resonance frequency is shown in Fig. 1(a). The surface current direction is highlighted by the light blue arrow. Its 3-D directivity pattern indicates that it performs as an electric dipole oriented along the $x$-axis [31].

Next, the EAD NFRP element and the electric dipole are modified by bending both halves towards each other in the plane orthogonal to the center line. The electric size of the antenna is reduced to $k a \sim 0.711$. The surface current density distribution on the top surface of this modified EAD NFRP element and its 3-D radiation pattern is shown in Fig. 1(b) at its resonance frequency. It is observed that the surface currents on the bent EAD NFRP element and its 3-D directivity pattern exhibit behaviors essentially the same as the unbent one. Its 
radiation efficiency remains high ( $89 \%$ ), indicating that the impact of the bent configuration is small. Thus, it is concluded that this modification can decrease the electrical size of the antenna without impacting its radiation pattern or its impedance matching performance.

\section{B. Wideband directive antenna}

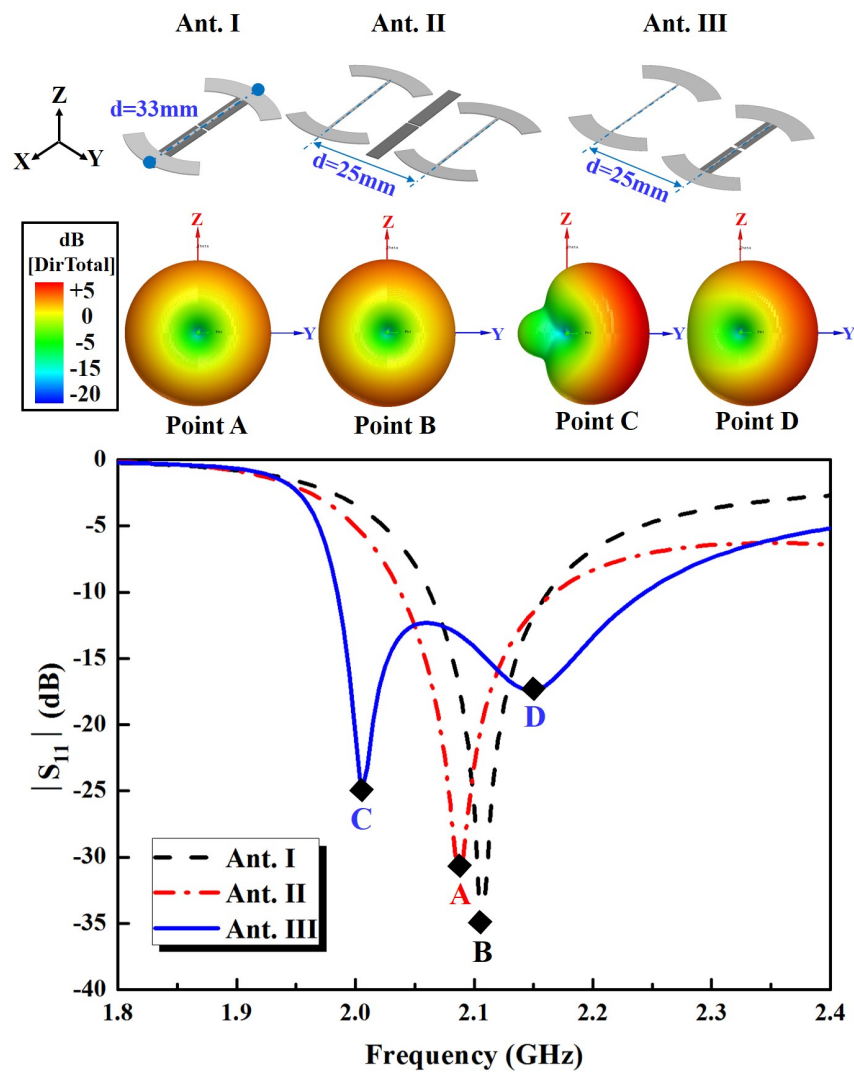

Fig. 2 Design evolution leading to the wideband and directional properties. Simulated $\left|S_{11}\right|$ values as a function of the source frequency and the 3-D directivity patterns associated with these designs.

The wideband and directional operating principles of the antenna were realized through a series of cases and their comparisons. The reflection coefficients as functions of the source frequency together with the corresponding 3-D directivity patterns for three designs are given in Fig. 2. Ant. I is the same EAD NFRP element combined with the center-fed dipole introduced in Fig. 1(a). Ant. II consists of the EAD NFRP element and a duplicate, each parallel to and separated from the driven dipole in opposite directions in the same plane. These two EAD NFRP elements are resonant simultaneously when the dipole is driven at $2.07 \mathrm{GHz}$. The resulting impedance bandwidth and 3-D directivity pattern are almost the same as those of Ant. I.

Ant. III presents an in-between design. The two EAD NFRP elements of Ant. II remain in the same position while the center-fed dipole is shifted along the $+y$-axis until it is under one of the EAD elements (or consider it to be Ant. I with another EAD element integrated with it in the same plane as its NFRP element). Because these NFRP elements now experience different capacitive couplings between each other and the driven element, they are no longer resonant at the same frequency point.

As Fig. 2 illustrates, the introduction of this overlapping second resonance dramatically increases the overall bandwidth. As shown in Fig. 2, Ant. III is resonant at two frequencies: 2.005 and $2.15 \mathrm{GHz}$. The consequent $-10 \mathrm{~dB}$ fractional impedance bandwidth is $12.16 \%$. Moreover, it was also found that when the center-fed dipole was positioned underneath the NFRP element offset along the $+y$-axis, a directive end-fire radiation pattern along the $+y$-axis was attained. Furthermore, the main beam direction remained oriented along the $+y$-axis over the entire operational frequency range. The directivity and FTBR values at the noted two resonance frequencies are 6.33 $\mathrm{dBi}$ and $11.25 \mathrm{~dB}$, and $4.12 \mathrm{dBi}$, and $7.68 \mathrm{~dB}$, respectively. An obvious interpretation of Ant. III's configuration is that it is a type of "quasi-Yagi" antenna, the NFRP element along the $-y$-axis acting as its reflector. Note that it was also found from the simulation studies that if the center-fed dipole were shifted along the $-y$-axis to be below the other EAD NFRP element, the resulting antenna would exhibit the same performance as Ant. III except that the main-beam direction of its 3-D directivity pattern would then be along the $-y$-axis. Note that the distance between the two NFRP elements $(25 \mathrm{~mm})$ was optimized to be approximately $0.18 \lambda_{0}$. As discussed next, this value provided the proper phase delay between them $(\sim \pi / 2)$ to achieve the desired quasi-Yagi behavior.

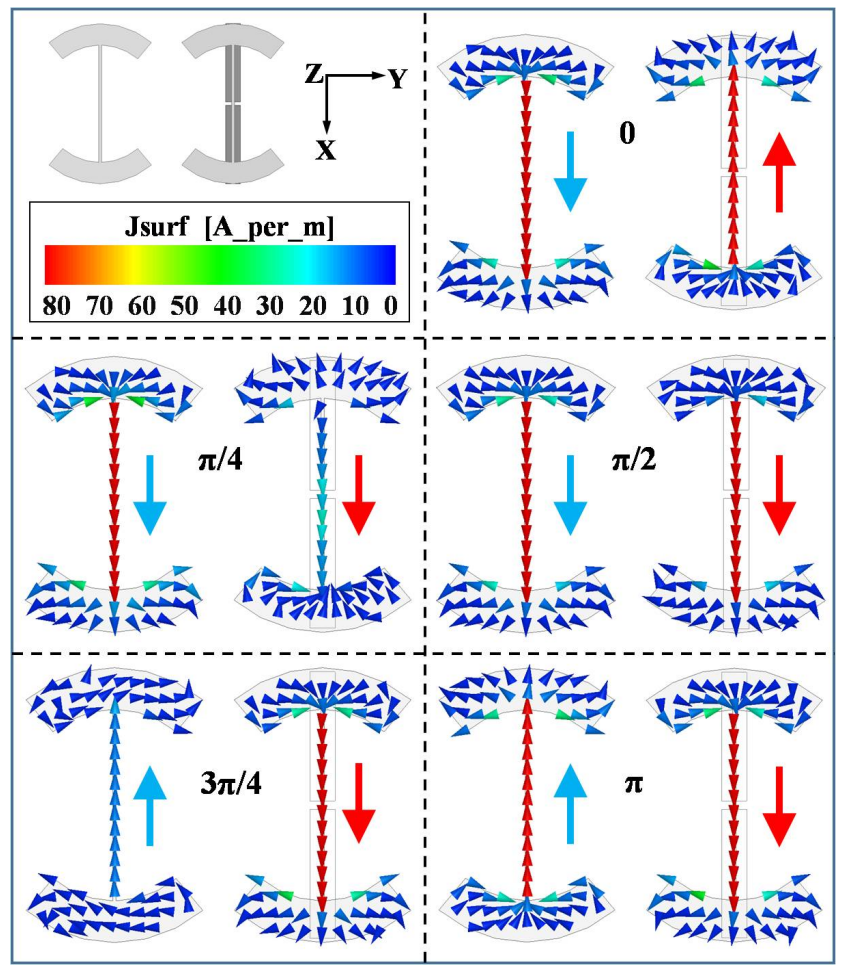

Fig. 3 Surface current density distributions on the upper surfaces of the two EAD NFPR elements over one half period (corresponding to a $\pi$ phase change), where the period $\mathrm{T}=1 / \mathrm{f}, \mathrm{f}=2.04 \mathrm{GHz}$.

The surface current density distributions on the upper surfaces of the two NFRP elements of Ant. III are shown in Fig. 3 over the half period corresponding to $2.04 \mathrm{GHz}$, an arbitrary frequency point within its operating range. They provide an explanation of the formation of this quasi-Yagi antenna 
behavior. The source phase was varied and the results are presented at multiples of $\pi / 4$. The main directions of the currents are highlighted with the additional arrows: blue (red) represents the current flowing on the left (right) EAD NFRP element. Within the half period, the current direction on the right element remains the same in the range $(\pi / 4, \pi)$ while it remains unchanged in the range $(0, \pi / 2)$ on the left one. Consequently, there is a stable phase delay of $\sim \pi / 2$ between two elements. Moreover, the right one leads the phase change when compared to the left one. Therefore, in a quasi-Yagi sense, it is thus recognized that the right one serves as the driven element, and the left one serves as the reflector [30]. This behavior is similar to that in the previous two-element array study given in [28].

\section{ANTENNA DESIGN}

With the realization that (1) the compact bent design provides approximately the same behavior as the straight version shown in Fig. 1 of Section II-A and (2) the design evolution led to the wideband and directional properties demonstrated in Fig. 2 of Section II-B, two of the bent elements were systematically integrated together to determine if their combination would produce the same effects as Ant. III did. The outcome was positive. Fig. 4 shows the final configuration and its design parameters of the pattern-configurable, flexible, wideband, electrically small NFRP antenna. The optimized values of those design parameters are given in Table I.

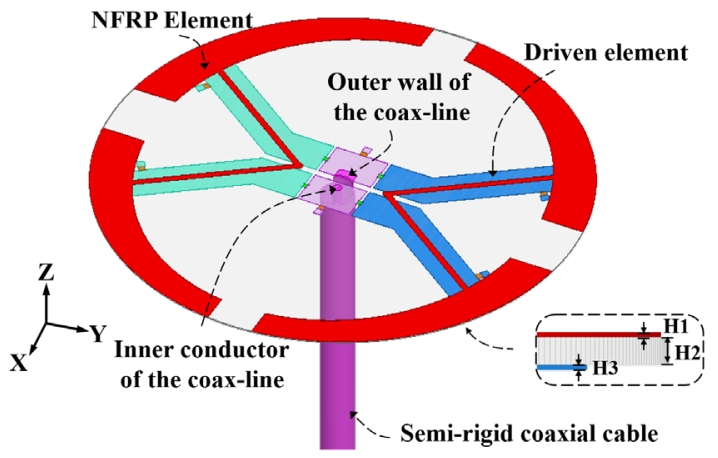

(a)

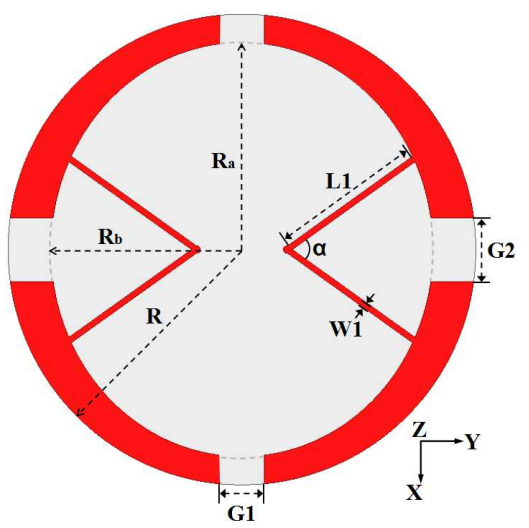

(b)

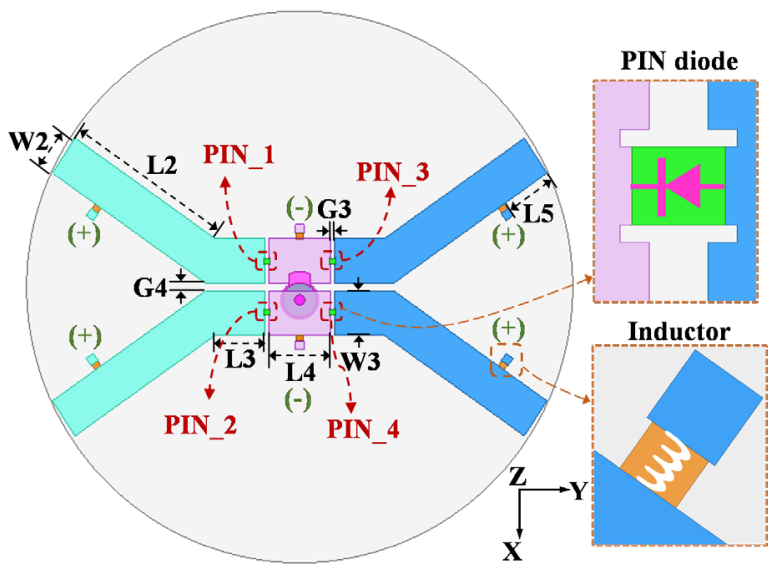

(c)

Fig. 4 Configuration of the pattern-reconfigurable, flexible, wideband, electrically small NFRP antenna. (a) 3-D isometric view. (b) Top view of the NFRP elements. (c) Top view of the driven element.

TABLE I. THE OPTIMIZED Design PARAMETERs OF THE PATTERNRECONFIGURABLE NFRP ANTENNA (DIMENSIONS IN MILLIMETERS)

\begin{tabular}{|c|c|c|c|}
\hline $\mathrm{Ra}=22.009$ & $\mathrm{Rb}=20.433$ & $\mathrm{R}=25$ & $\mathrm{~L} 1=16.38$ \\
\hline $\mathrm{L} 2=15.74$ & $\mathrm{~L} 3=4.58$ & $\mathrm{~L} 4=5.7$ & $\mathrm{~L} 5=4.83$ \\
\hline $\mathrm{W} 1=0.61$ & $\mathrm{~W} 2=3.80$ & $\mathrm{~W} 3=4$ & $\mathrm{G} 1=4.8$ \\
\hline $\mathrm{G} 2=6.8$ & $\mathrm{G} 3=0.3$ & $\mathrm{G} 4=0.76$ & $\mathrm{~h} 1=0.017$ \\
\hline $\mathrm{h} 2=0.127$ & $\mathrm{~h} 3=0.017$ & $\alpha=70.86^{\circ}$ & NULL \\
\hline
\end{tabular}

The antenna was fabricated using printed circuit board (PCB) technology and with a single Rogers Duroid 5880 substrate with relative permittivity and permeability, respectively, $\varepsilon_{r}=$ 2.2 and $\mu_{\mathrm{r}}=1.0$, and loss tangent $\tan \delta=0.0009$. The substrate was $0.127-\mathrm{mm}$ thick and the antenna elements were etched from its $0.5-\mathrm{oz}$ ( $17 \mu \mathrm{m}$ thick) copper on both sides. The overall shape is a disk whose radius is $25.0 \mathrm{~mm}$. These choices made the design symmetric, simple, and compact for the intended 1.8 $\mathrm{GHz}$ range of operation.

As shown in Fig. 4(a) and (b), the pair of bent NFRP elements realizing the quasi-Yagi performance were etched on the upper surface of the substrate. They were bent symmetrically with respect to the $y$-axis to the same angle, $\alpha=$ $70.86^{\circ}$. They have the same dimensions and are in mirror symmetry with respect to the $x$-axis. On the back side of the substrate, as shown in Fig. 4(c), the driven dipole element is etched. It includes six metal strips connected by four PIN diodes. All of those diodes were M/A-COM MA4GP907 PIN diodes. According to its datasheet, each of these PIN diodes serves as a $4.0 \Omega$ resistor in its ON-state and as a $0.025 \mathrm{pF}$ capacitor in its OFF-state [32]. These diodes are denoted here as PIN_1, PIN_2, PIN_3 and PIN_4. PIN_1 (PIN_2) and PIN_3 (PIN_4) are directed opposite to each other, i.e., their negative poles are all set towards the center as depicted in Fig. 4(c). There also are six $56 \mathrm{nH}$ coil inductors installed as shown; they prevent any RF signal from entering into the DC bias network.

The ON-OFF switch operation of the PIN diodes causes one of the two bent EAD NFRP elements to act with the driven element, and the other to act as the reflector element. Two combined states of the four diodes produce these two directional states. When PIN_1 and PIN_2 are ON, and PIN_3 
and PIN_4 are OFF, the dipole strips along the $-y$-axis are connected to the internal and external conductors of coaxial cable, respectively. Consequently, this ON-OFF switch combination makes the left NFRP element act as the driven element and the right one act as the reflector element. This configuration produces the "quasi-Yagi" end-fire radiation pattern with the main beam pointing along the $-y$-direction. We denote this state as State-L (i.e., "L" stands for "Left"). Likewise, when PIN 3 and PIN 4 are ON, and PIN_1 and PIN_2 are OFF, the dipole strips along the $+y$-axis are connected to the internal and external conductors of coaxial cable, respectively. This state is denoted as State-R (i.e., " $R$ " stands for "Right"). State-L and State-R and their corresponding four diode states are summarized in Table II.

In order to ensure the locations of the PIN diodes during fabrication of the prototype, four small rectangular slots are etched on both sides of the diode position as markers. They are $0.1 \mathrm{~mm} \times 0.06 \mathrm{~mm}$ in size. These slots provide two pads, 0.385 $\mathrm{mm} \times 0.06 \mathrm{~mm}$ in size, for the diodes. This arrangement is shown in the enlarged subplot in Fig. 4(c). A KTG 141-50 type, semi-rigid, $50 \Omega$ coaxial cable was selected to be connected to the driven element. As shown in Fig. 4(a), its internal and external conductors are soldered to the two isolated metal strips at the center of the driven dipole element.

TABLe II. The PIN Diode States For the Two Pattern States

\begin{tabular}{|c|c|c|c|c|}
\hline State & PIN_1 & PIN_2 & PIN_3 & PIN_4 \\
\hline L & ON & ON & OFF & OFF \\
\hline R & OFF & OFF & ON & ON \\
\hline
\end{tabular}

\section{Simulated Antenna PERFormance AND EXPERIMENTAL VALIDATION}

The performance characteristics of the optimized design in Fig. 4 in Section III were investigated both numerically and experimentally. Photos of the fabricated prototype are shown in Fig. 5. Because the balanced driven dipole was directly connected to the unbalanced $50 \Omega$ coaxial cable as shown in Fig. 4(a), a $39.5 \mathrm{~mm}$ long sleeve balun was employed only in the measurements to eliminate the influence of the leakage currents that could occur on the outer wall of the cable [33]. With the aid of the balun, the antenna under test (AUT) thus maintained the predicted impedance matching and far-field directivity pattern characteristics.
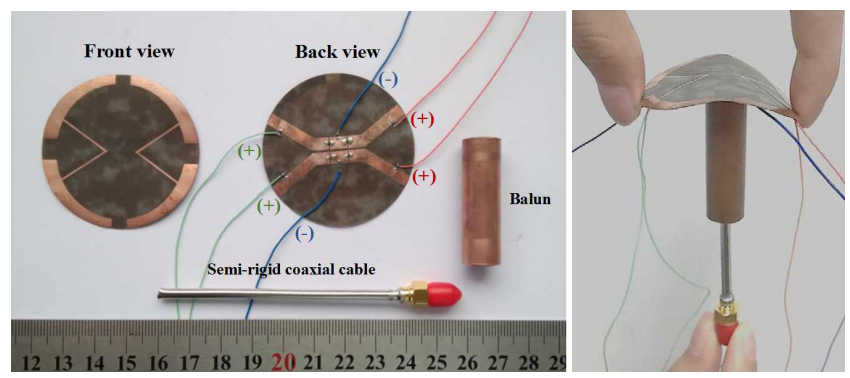

(a)

(b)

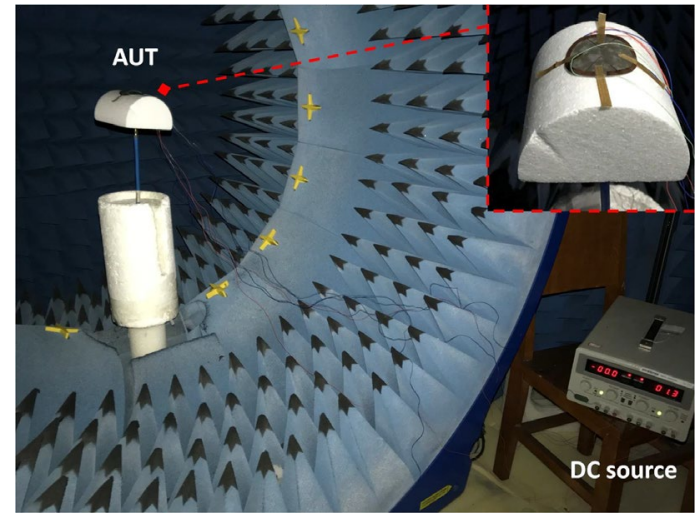

(c)

Fig. 5 Fabricated pattern-reconfigurable ESA prototype in the anechoic chamber with the measurement sleeve balun installed. (a) Antenna elements before the assembly. (b) Side view of the prototype antenna after its assembly. (c) Prototype antenna as the AUT in the chamber.

A GWinstek GPC-3060D dc voltage-stabilized power supply fed $\sim 1.40 \mathrm{~V}$ to the diodes. As shown in Fig. 5(a), three different pairs of dc bias lines were used to switch the diodes between their ON and OFF states. State-L employs two green ("+" pole) and two blue ("-" pole) dc lines; State-R employs two red ("+" pole) and two blue ("--" pole) dc lines.

The reflection coefficients $\left(\left|\mathrm{S}_{11}\right|\right.$ values) of those two states were measured as a function of the excitation frequency using an Agilent E5063A PNA Vector Network Analyzer (VNA). The measured and simulated results of these two states are presented in Fig. 6(a). We note that the simulated results for State-L are the same as those for State-R due to the symmetric configuration. The simulated $-10 \mathrm{~dB}$ impedance bandwidth is from 1.676 to $1.916 \mathrm{GHz}(240 \mathrm{MHz})$, which corresponds to a fractional bandwidth of $13.4 \%$. The results clear show that there are two resonance frequencies within this range: 1.708 and $1.798 \mathrm{GHz}$ which, as explained, increases the operational bandwidth. The measured $-10 \mathrm{~dB}$ impedance bandwidths for State-L and State-R are $232 \mathrm{MHz}$ from 1.683 to $1.915 \mathrm{GHz}$ $(12.9 \%)$ and $238 \mathrm{MHz}$ from 1.677 to $1.915 \mathrm{GHz}(13.3 \%)$, respectively. The measured and simulated results are in good agreement. The simulated peak gain, realized gain, directivity and front-to-back ratio values are depicted in Fig. 6(b) as functions of the source frequency. The antenna exhibits the desired end-fire radiation characteristics over the entire operational band. Note that the gain and FTBR values at the lower frequencies are larger than those at the higher frequencies. Moreover, we note that in our simulation study the angle $\alpha$ was set initially at $90^{\circ}$. The corresponding fractional bandwidth, peak realized gain, radiation efficiency, and front-to-back ratio values were $11.5 \%, 4.64 \mathrm{dBi}, 79.93 \%$, and $22.86 \mathrm{~dB}$, respectively. When angle $\alpha$ was optimized to the value $70.86^{\circ}$, these values became $13.4 \%, 4.78 \mathrm{dBi}, 80.6 \%$, and $16.15 \mathrm{~dB}$, respectively. Clearly, the fractional bandwidth, peak realized gain, and radiation efficiency were improved at the cost of a slight decrease in the front-to-back ratio value. 


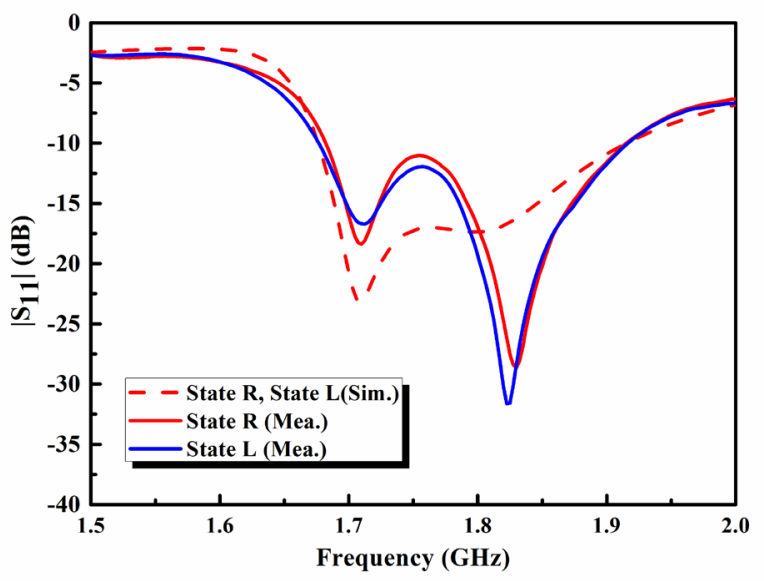

(a)

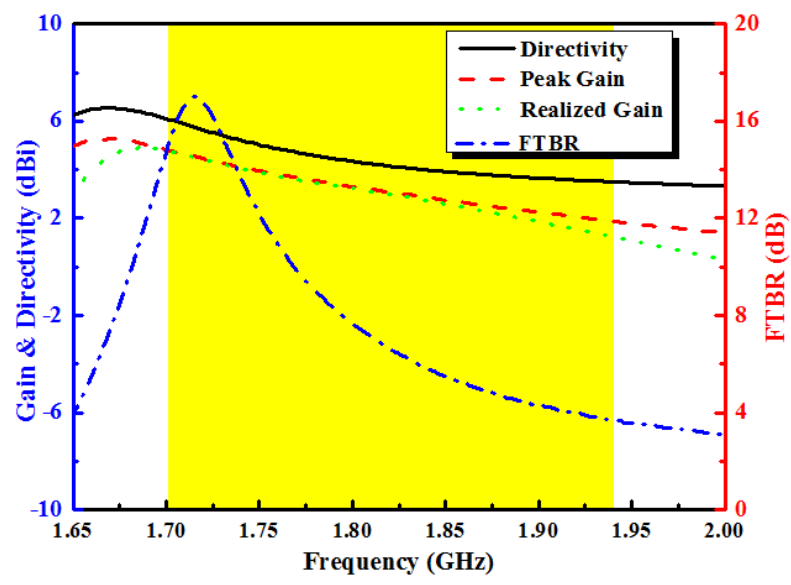

(b)

Fig. 6 Performance characteristics of the pattern-reconfigurable ESA. (a) The measured and simulated reflection coefficient $\left(\left|\mathbf{S}_{11}\right|\right)$ values. (b) The simulated directivity, peak gain, realized gain, and front-to-back ratio values as functions of the source frequency in both pattern-reconfigurable states. The simulated $-10 \mathrm{~dB}$ impedance bandwidth range is highlighted in yellow.

The far-field radiation performances were then measured in an anechoic chamber at the National Key Laboratory of Science and Technology on Communications, University of Electronic Science and Technology of China. This facility is mainly based on the Agilent N5230A PNA-L VNA and the SATIMO passive measurement system $(0.8-6 \mathrm{GHz})$ [34]. The prototype was measured by being mounted on a flat foam pedestal in the chamber. The corresponding measured and simulated realized gain patterns in State- $\mathrm{L}$ and State- $\mathrm{R}$ are presented and compared at the two resonance frequencies in Fig. 7. The measured and simulated values of the prototype in both states are summarized in Table III. The measured and simulated results for both frequencies are in reasonable agreement. The differences between the measured and simulated values have been confirmed through simulations to be a consequence of fabrication, assembly, and test errors, particularly arising from the very thin and soft nature of the antenna's substrate.

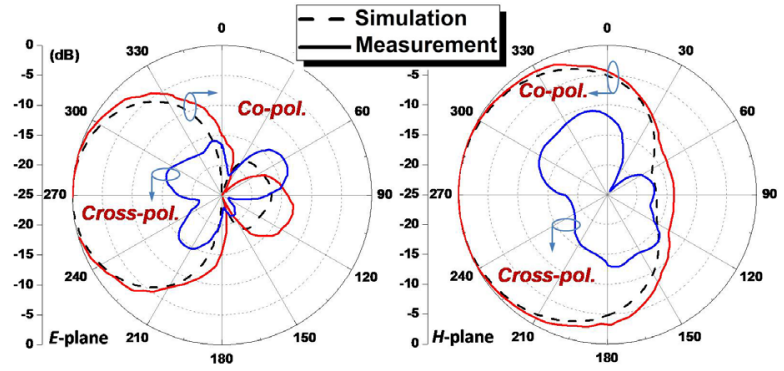

(a)

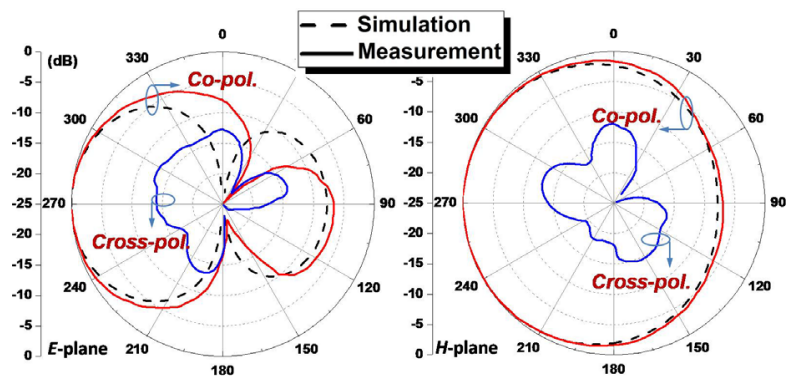

(b)

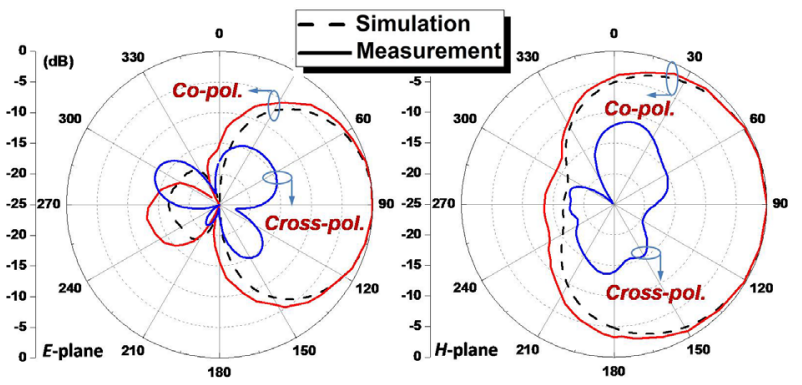

(c)

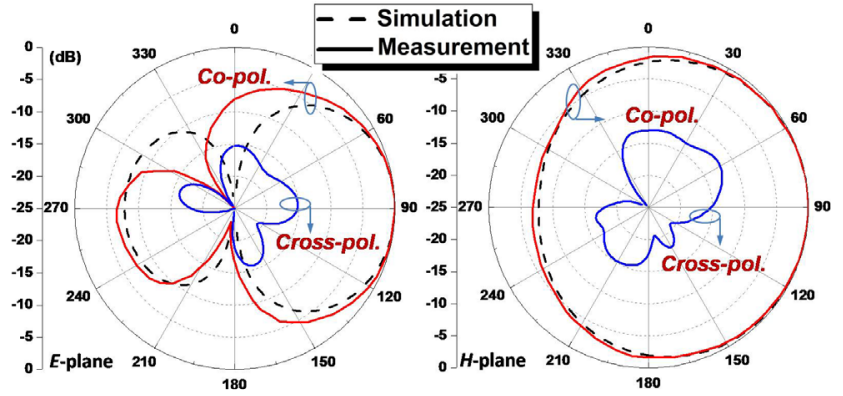

(d)

Fig. 7 Measured and simulated normalized realized gain patterns in the $E$ - and $\mathrm{H}$ - planes at the two resonance frequency points of State-L: (a) 1.708, and (b) $1.798 \mathrm{GHz}$; and of State-R: (c) 1.708 , and (d) $1.798 \mathrm{GHz}$.

The surface current distributions on the upper surface of the two EAD NFRP elements were investigated further to confirm the operational mechanisms of this directional configuration. They are illustrated in Fig. 8 for State-R over a half period corresponding to its first resonance frequency, $1.708 \mathrm{GHz}$. The effective directions of these surface currents are again highlighted with the blue (left NFRP element) and red (right NFRP element) arrows. The two EAD elements have the same electrical size and are separated by a small distance, approximately $0.15 \lambda_{0}$, which is slightly closer than in the Ant. III in Fig. 2. Again, this optimized value provides the proper 
phase delay to achieve the quasi-Yagi behavior. Again, the source phase was varied and the results are presented at multiples of $\pi / 4$. As observed in the straight configuration in Fig. 3, the phase of left NFRP element always has a lag of $\pi / 2$ when compared to the right NFRP element when the antenna operates in its State-R. Likewise, the phase of the right NFRP element is delayed by $\pi / 2$ relative to the left NFRP element when it operates in its State-L.

Table III. Measured (M) And Simulated (S) Performance CHARACTERISTICS OF THE PATTERN-RECONFIGURABLE ESA

\begin{tabular}{|c|c|c|c|c|c|}
\hline \multicolumn{2}{|c|}{$\begin{array}{c}\text { Performance } \\
\text { Characteristic }\end{array}$} & $\begin{array}{c}\text { Fractional } \\
\text { Bandwidth } \\
(\%)\end{array}$ & $\begin{array}{c}\text { Maximum } \\
\text { Realized } \\
\text { Gain (dB) }\end{array}$ & $\begin{array}{c}\text { Radiation } \\
\text { Efficiency } \\
(\%)\end{array}$ & $\begin{array}{c}\text { Maximum } \\
\text { FTBR } \\
(\mathrm{dB})\end{array}$ \\
\hline \multirow{2}{*}{ State-L } & $\mathrm{S}$ & 13.4 & 4.78 & 80.6 & 16.15 \\
\cline { 2 - 6 } & $\mathrm{M}$ & 12.9 & 4.40 & 70.5 & 13.27 \\
\hline \multirow{2}{*}{ State-R } & $\mathrm{S}$ & 13.4 & 4.78 & 80.6 & 16.15 \\
\cline { 2 - 6 } & $\mathrm{M}$ & 13.3 & 4.43 & 70.3 & 13.56 \\
\hline
\end{tabular}

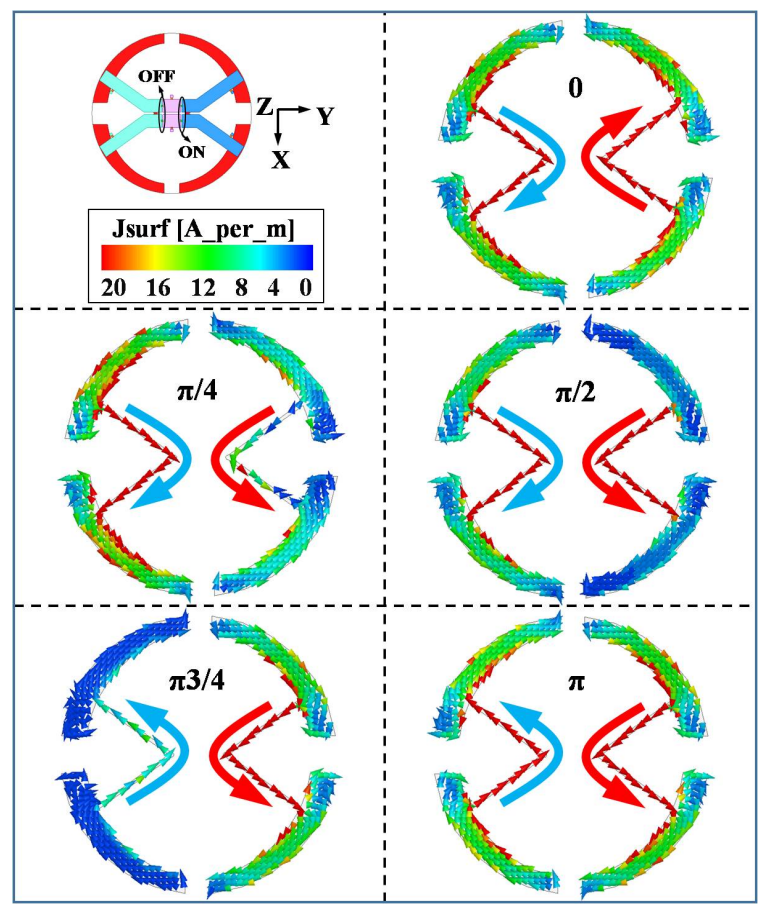

Fig. 8. Simulated State-R surface current density distributions on the upper surfaces of the pattern-reconfigurable antenna's EAD NFRP elements over a half-period defined by the first resonance frequency, $1.708 \mathrm{GHz}$, within its operational range.

\section{FleXiBILITY}

Because its substrate is very thin, the prototype pattern-reconfigurable antenna has the capability to be folded, rolled, or bent with no structural damage. To confirm the practical usefulness of this structural quality, its radiation characteristics were tested in several conformal arrangements both numerically and experimentally. In particular, it was affixed on styrofoam cylinders possessing different radii by being bent relative to their horizontal (along the $x$-) and vertical (along the $y$-) axes. The photo of one example is shared in Fig. 5(c). Considering the symmetry of antenna structure itself, only the antenna's performance in its State- $\mathrm{R}$ is reported here. The State- $\mathrm{L}$ results were found to be the same.

Table IV. Measured (M) and Simulated (S) Performance CHARACTERISTICS OF THE FLEXIBLE PATTERN-ReCONFIGURABLE ANTENNA WHEN IT IS MOUNTED CONFORMALLY ON CYLINDERS WITH DIFFERENT RADII of Curvature Under Two SeParate BEnding Conditions

(a) Bending condition with respect to the $y$-axis (cylinder axis)

\begin{tabular}{|c|c|c|c|c|c|}
\hline \multicolumn{2}{|l|}{ Category } & $50 \mathrm{~mm}$ & $70 \mathrm{~mm}$ & $90 \mathrm{~mm}$ & $110 \mathrm{~mm}$ \\
\hline \multirow{2}{*}{$\begin{array}{c}\text { Operational } \\
\text { Frequency } \\
\text { Range } \\
(\mathrm{GHz})\end{array}$} & $\mathrm{S}$ & $\begin{array}{c}1.676 \sim \\
1.92\end{array}$ & $\begin{array}{c}1.676 \sim \\
1.92\end{array}$ & $\begin{array}{c}1.674 \sim \\
1.912\end{array}$ & $\begin{array}{c}1.676 \sim \\
1.910\end{array}$ \\
\hline & M & $\begin{array}{l}1.670 / \\
1.932\end{array}$ & $\begin{array}{l}1.673 / \\
1.937\end{array}$ & $\begin{array}{l}1.677 / \\
1.918\end{array}$ & $\begin{array}{l}1.673 / \\
1.910\end{array}$ \\
\hline \multirow{2}{*}{$\begin{array}{c}\text { Two } \\
\text { Resonance } \\
\text { Frequency } \\
\text { Points } \\
(\mathrm{GHz}) \\
\end{array}$} & $\mathrm{S}$ & $\begin{array}{l}1.706 / \\
1.810\end{array}$ & $\begin{array}{l}1.708 / \\
1.806\end{array}$ & $\begin{array}{l}1.704 / \\
1.802\end{array}$ & $\begin{array}{l}1.706 / \\
1.800\end{array}$ \\
\hline & M & $\begin{array}{l}1.700 / \\
1.8425 \\
\end{array}$ & $\begin{array}{l}1.703 / \\
1.847 \\
\end{array}$ & $\begin{array}{l}1.705 / \\
1.830 \\
\end{array}$ & $\begin{array}{l}1.705 / \\
1.820 \\
\end{array}$ \\
\hline \multirow{2}{*}{$\begin{array}{l}\text { Bandwidth } \\
\text { (MHz) }\end{array}$} & $\mathrm{S}$ & 244 & 244 & 238 & 234 \\
\hline & M & 262 & 264 & 241 & 237 \\
\hline \multirow{2}{*}{$\begin{array}{c}\text { Fractional } \\
\text { Bandwidth } \\
(\%)\end{array}$} & $\mathrm{S}$ & 13.6 & 13.6 & 13.3 & 13.1 \\
\hline & M & 14.5 & 14.6 & 13.4 & 13.2 \\
\hline \multirow{2}{*}{$\begin{array}{c}\text { Maximum } \\
\text { Realized } \\
\text { Gain } \\
(\mathrm{dB}) \\
\end{array}$} & $\mathrm{S}$ & 4.7046 & 4.7712 & 4.7588 & 4.7656 \\
\hline & M & 3.9257 & 3.9742 & 4.0081 & 3.9190 \\
\hline \multirow{2}{*}{$\begin{array}{c}\text { Radiation } \\
\text { Efficiency } \\
(\%)\end{array}$} & $\mathrm{S}$ & 78.93 & 78.75 & 78.26 & 77.98 \\
\hline & $\mathrm{M}$ & 67.57 & 66.76 & 67.88 & 67.36 \\
\hline \multirow{2}{*}{$\begin{array}{l}\text { Maximum } \\
\text { FTBR } \\
(\mathrm{dB})\end{array}$} & $\mathrm{S}$ & 15.4128 & 15.9968 & 15.3611 & 15.2254 \\
\hline & M & 12.71 & 12.86 & 13.52 & 13.43 \\
\hline
\end{tabular}

(b)Bending condition with respect to the $x$-axis (perpendicular to cylinder axis)

\begin{tabular}{|c|c|c|c|c|c|}
\hline \multirow{2}{*}{\multicolumn{2}{|c|}{ Category }} & $50 \mathrm{~mm}$ & $70 \mathrm{~mm}$ & $90 \mathrm{~mm}$ & $110 \mathrm{~mm}$ \\
\hline & & & & & \\
\hline \multirow{2}{*}{$\begin{array}{c}\text { Operational } \\
\text { Frequency } \\
\text { Range } \\
(\mathrm{GHz})\end{array}$} & $\mathrm{S}$ & $\begin{array}{l}1.688 / \\
1.830\end{array}$ & $\begin{array}{l}1.686 / \\
1.864\end{array}$ & $\begin{array}{l}1.684 / \\
1.882\end{array}$ & $\begin{array}{l}1.682 / \\
1.888\end{array}$ \\
\hline & $\mathrm{M}$ & $\begin{array}{l}1.668 / \\
1.925\end{array}$ & $\begin{array}{l}1.668 / \\
1.908\end{array}$ & $\begin{array}{l}1.675 / \\
1.910\end{array}$ & $\begin{array}{l}1.678 / \\
1.915\end{array}$ \\
\hline \multirow{2}{*}{$\begin{array}{c}\text { Two } \\
\text { Resonance } \\
\text { Frequency } \\
\text { Points } \\
(\mathrm{GHz})\end{array}$} & $\mathrm{S}$ & $\begin{array}{l}1.708 / \\
1.792\end{array}$ & $\begin{array}{l}1.712 / \\
1.794\end{array}$ & $\begin{array}{l}1.712 / \\
1.790\end{array}$ & $\begin{array}{l}1.712 / \\
1.794\end{array}$ \\
\hline & $\mathrm{M}$ & $\begin{array}{l}1.700 / \\
1.837\end{array}$ & $\begin{array}{l}1.703 / \\
1.825\end{array}$ & $\begin{array}{l}1.705 / \\
1.822\end{array}$ & $\begin{array}{l}1.712 / \\
1.822\end{array}$ \\
\hline \multirow{2}{*}{$\begin{array}{l}\text { Bandwidth } \\
(\mathrm{MHz})\end{array}$} & $\mathrm{S}$ & 142 & 178 & 198 & 206 \\
\hline & $\mathrm{M}$ & 257 & 240 & 235 & 237 \\
\hline \multirow{2}{*}{$\begin{array}{c}\text { Fractional } \\
\text { Bandwidth } \\
\quad(\%)\end{array}$} & $\mathrm{S}$ & 8.1 & 10.0 & 11.1 & 11.5 \\
\hline & $\mathrm{M}$ & 14.3 & 13.4 & 13.1 & 13.2 \\
\hline \multirow{2}{*}{$\begin{array}{l}\text { Maximum } \\
\text { Realized } \\
\text { Gain } \\
\text { (dB) }\end{array}$} & $\mathrm{S}$ & 4.7844 & 4.6902 & 4.7368 & 4.7041 \\
\hline & $\mathrm{M}$ & 3.792 & 3.865 & 4.227 & 3.8152 \\
\hline \multirow{2}{*}{$\begin{array}{c}\text { Radiation } \\
\text { Efficiency } \\
(\%)\end{array}$} & $\mathrm{S}$ & 70.31 & 71.11 & 72.83 & 73.87 \\
\hline & $\mathrm{M}$ & 62.76 & 65.43 & 63.00 & 63.54 \\
\hline \multirow{2}{*}{$\begin{array}{l}\text { Maximum } \\
\text { FTBR } \\
(\mathrm{dB})\end{array}$} & $\mathrm{S}$ & 11.2826 & 11.8050 & 13.6396 & 14.3595 \\
\hline & $\mathrm{M}$ & 9.72 & 9.97 & 11.31 & 12.62 \\
\hline
\end{tabular}


Table IV gives the measured and simulated values of the prototype when it was mounted conformally on cylinders of radii equal to 50,70,90, and $110 \mathrm{~mm}$ in both bending conditions. As shown in the Table IV (a), when the antenna is bent along the $y$-axis, the measured $-10 \mathrm{~dB}$ impedance bandwidth in all of the configurations is shifted only slightly when compared to the planar condition and the values are in good agreement with the simulated ones. The maximal simulated shift was $6.0 \mathrm{MHz}$, a significantly small fraction (2.5\%) of the $240 \mathrm{MHz}$ bandwidth. Moreover, the measured max RG, RE, and FTBR values also changed only slightly from their simulated values.

The radiation characteristics of the cases in which the prototype was conformal and bent along the $x$-axis are listed in Table IV (b). One observes that the simulated -10dB impedance bandwidths of all of these configurations witnessed only a small decrease when compared with the planar configuration. Moreover, the measured max RG, RE, and FTBR results also change only slightly from their simulated values. On the other hand, there are more significant differences between the bandwidth values for the bent and planar cases. For instance, the simulated maximum bandwidth shift is $98 \mathrm{MHz}$ when the cylinder radius is $50 \mathrm{~mm}$. This behavior appears to have arisen from significantly bending the center elements of the EAD where the bias lines are attached. In the y-axis bend case, the two symmetric sides are bent more gently around those center elements. It must be noted that in both bending modes, the radiation efficiency is not very high, $\sim 74 \%$ in simulation and $\sim 65 \%$ in measurement. This loss phenomenon is ascribed to the actual resistance of the PIN diodes. According to our simulation studies, when the resistance is changed from $4.0 \Omega$ to $0 \Omega$ as noted from the data sheets, the radiation efficiency is higher than $85 \%$ in each case in Table IV. It indicates that the actual resistance of the PIN diodes decreases the radiation efficiency $\sim 15 \%$.

To test the impact of a conformal placement of the antenna on a dielectric substrate, simulation studies were performed with the material properties of the cylinder changed from styrofoam to glass_PTFEreinf, whose relative permittivity $\varepsilon_{r}=$ 2.5 , permeability $\mu_{r}=1.0$, and loss tangent $\tan \delta=0.002$. The antenna was placed in the $y$-axis bending condition directly on a glass_PTFEreinf cylinder having a $50.0 \mathrm{~mm}$ radius of curvature. The simulation results demonstrate that the antenna performs well even when it is placed on a higher dielectric constant material. Its operational band became $1.676-1.458 \mathrm{GHz}$, i.e., the band was red-shifted by $218 \mathrm{MHz}$ due to the increased relative permittivity of the material. Its simulated fractional bandwidth, peak realized gain, radiation efficiency, and front-to-back ratio values were, respectively, $11.14 \%, 3.5 \mathrm{dBi}$, $75 \%$, and $10.8 \mathrm{~dB}$. Thus, the antenna mounted conformally on a cylindrical glass substrate maintained good end-fire radiation performance within its new operational frequency band.

In contrast to the many previously reported compact directional antennas, the reported antenna not only has an electrically smaller size and wider bandwidth, but also possesses additional advantages, notably its pattern-reconfigurability and flexibility. Table $\mathrm{V}$ provides a direct comparison with recently reported compact antennas. The total electrical size, $k a$, bandwidth, peak realized gain value for each reconfigurable state, reconfigurability, and flexibility are listed. Note that for a fair comparison, the total electrical sizes of the reported designs correspond to the center operational frequency points within the $-10 \mathrm{~dB}$ impedance bandwidth. Table IV demonstrates that our measured prototype has a wide bandwidth, high realized gain, and is electrically small with $k a<1$, while being pattern-reconfigurable and flexible.

TABle V. COMPARisons of THE Performance CHARACTERISTIC OF THE PATTERN-RECONFIGURABLE, FleXIBLE, WidEBAND, DiRECTIVE, EleCtrically SMALl ANTENNA IN ITS PlanAR CONFIGURATION WITH RELATED ANTENNAS REPORTED IN THE LITERATURE

\begin{tabular}{|c|c|c|c|c|c|}
\hline Refs. & $k a$ & BW (\%) & $\begin{array}{c}\text { Peak realized } \\
\text { gain } \\
(\mathrm{dBi})\end{array}$ & Reconfigurable & Flexible \\
\hline$[4]$ & 1.70 & 6.2 & 6.3 & no & no \\
\hline$[5]$ & 2.81 & 16 & $6.4 / 3.6 / 6.2$ & yes & no \\
\hline$[35]$ & 0.97 & 2 & 3.57 & no & yes \\
\hline$[36]$ & 1.18 & 0.23 & 7.2 & no & no \\
\hline$[37]$ & 1.72 & 13.8 & 6 & no & no \\
\hline$[38]$ & 3.35 & 11 & 5.2 & no & no \\
\hline$[39]$ & 1.45 & 5.06 & 5.76 & no & yes \\
\hline$[40]$ & 1 & $<4.8$ & 7.0 & no & no \\
\hline Rep. Ant. & 0.94 & 12.9 & $4.43 / 4.43$ & yes & yes \\
\hline
\end{tabular}

\section{CONCLUSION}

The design, simulations, and experimental validation of the performance characteristics of a novel wideband, electrically small, pattern-reconfigurable, flexible, directive, NFRP antenna were presented in a comprehensive manner. The antenna consists of a pair of NFRP elements and a coax-fed driven dipole element. Through modifications of past EAD NFRP element designs, an electrically small size, $\mathrm{ka} \sim 0.94$, was realized. Moreover, by integrating four PIN diodes into the driven element, the antenna was made reconfigurable, producing end-fire directive realized gain patterns that point in diametrically opposite directions. The principles of operation of this antenna and its realization were described. The measured results of this prototype are all in reasonable agreement with their simulated values. Discrepancies were explained. The electrically small measured planar prototype exhibited a wide impedance bandwidth, $\sim 13.1 \%$ and a stable gain of $\sim 4.42 \mathrm{dBi}$ in both its directive states. Its flexibility was investigated with simulations and experiments of several conformal configurations. It was confirmed that the antenna exhibited stable radiation performance characteristics in these various bending conditions. This type of antenna could be attractive for many evolving ITS systems.

\section{References}

[1] F. Liu, Z. J. Zhang, W. H. Chen, Z .H. Feng, and M. F. Iskander, “An endfire beam-switchable antenna array used in vehicular environment," IEEE Antennas Wireless Propag. Lett., vol. 9, pp. 195-198, 2010.

[2] A. Cidronali, S. Maddio, M. Passafiume, and G. Manes, "Car talk: technologies for vehicleto-roadside communications," IEEE Microw. Mag., vol. 17, no. 11, pp. 40-60, Nov. 2016.

[3] S. Poochaya and P. Uthansakul, "Beam tracking in switched-beam antenna system for V2V communication," Int. J. Antennas Propag., vol. 2016, Article ID 4169619, pp. 1-12, 2016.

[4] Q. Xin, F.-S. Zhang, B.-H. Sun, Y.-L. Zou, and Q.-Z. Liu, "Yagi-uda antenna with small size for vehicles," Electron. Lett., vol. 47, no. 7, pp. 428-430, 2011. 
[5] J. Ren, X. Yang, J. Y. Yin, and Y. Z. Yin, "A novel antenna with reconfigurable patterns using $\mathrm{H}$-shaped structures," IEEE Antennas Wireless Propag. Lett., vol. 14, pp. 915-918, 2015.

[6] D. Rodrigo and L. Jofre, "Frequency and radiation pattern reconfigurability of a multi-size pixel antenna," IEEE Trans. Antennas Propag., vol. 60, no. 5, pp. 2219-2225, May 2012.

[7] W. Lin, H. Wong, and R. W. Ziolkowski, "Wideband pattern-reconfigurable antenna with switchable broadside and conical beams," IEEE Antennas Wireless Propag. Lett., vol. 16, pp. 2638-2641, 2017.

[8] C. Lee and C. W. Jung, "Radiation-pattern-reconfigurable antenna using monopole-loop for Fitbit Flex Wristband," IEEE Antennas Wireless Propag. Lett., vol. 14, pp. 269-272, 2015.

[9] L. Zhong, J.-S. Hong, and H.-C. Zhou, "A novel pattern-reconfigurable cylindrical dielectric resonator antenna with enhanced gain," IEEE Antennas Wireless Propag. Lett., vol. 15, pp. 1253-1256, 2016.

[10] Z. Chen, and H. Wong, "Wideband glass and liquid cylindrical dielectric resonator antenna for pattern reconfigurable design," IEEE Trans. Antennas Propag., vol. 65, no. 5, pp. 2157-2164, May 2017.

[11] Y.-F. Cheng, X. Ding, W. Shao, and B.-Z. Wang, "Planar wide-angle scanning phased array with pattern-reconfigurable windmill-shaped loop elements," IEEE Trans. Antennas Propag., vol. 65, no. 2, pp. 932-936, Feb. 2017.

[12] J. X. Li, Q. S. Zeng, R. Z. Liu, and T. A. Denidni, "A compact dual-band beam-sweeping antenna based on active frequency selective surfaces," IEEE Trans. Antennas Propag., vol. 65, no. 4, pp. 1542-1549, Apr. 2017.

[13] V. T. Nguyen and C. W. Jung, "Radiation-pattern reconfigurable antenna for medical implants in MedRadio band," IEEE Antennas Wireless Propag. Lett., vol. 15, pp. 106-109, 2016.

[14] H. Li, B. K. Lau, and S. He, "Design of closely packed pattern reconfigurable antenna array for MIMO terminals," IEEE Trans. Antennas Propag., vol. 65, no. 9, pp. 4891-4896, Sep. 2017.

[15] C. Rhee, Y. Kim, T. Park, S. -S. Kwoun, B. Mun, B. Lee, C. Jung "Pattern-reconfigurable MIMO antenna for high isolation and low correlation," IEEE Antennas Wireless Propag. Lett., vol. 13, pp. 1373-1376, 2014

[16] N. Ramli, M. T. Ali, M. T. Islam, A. L. Yusof, and S. Muhamud-Kayat, "Aperture-coupled frequency and patterns reconfigurable microstrip stacked array antenna," IEEE Trans. Antennas Propag., vol. 63, no. 3, pp. 1067-1074, Mar. 2015.

[17] H. N. Chu and T.-G. Ma, "Beamwidth switchable planar microstrip series-fed slot array using reconfigurable synthesized transmission lines," IEEE Trans. Antennas Propag., vol. 65, no. 7, pp. 3766-3711, Jul. 2017.

[18] Y. Yang, R. B. V. B. Simorangkir, X. Zhu, K. Esselle, and Q. Xue, "A novel boresight and conical pattern reconfigurable antenna with the diversity of $360^{\circ}$ polarization scanning," IEEE Trans. Antennas Propag., vol. 65 , no. 11, pp. 5747-5756, Nov. 2017.

[19] M. A. Hossain, I. Bahceci, and B. A. Cetiner, "Parasitic layer based radiation pattern reconfigurable antenna for $5 \mathrm{G}$ communications," IEEE Trans. Antennas Propag., vol. 65, no. 12, pp. 6444-6452, Dec. 2017.

[20] M. S. Alam, and A. M. Abbosh, "Wideband pattern-reconfigurable antenna using pair of radial radiators on truncated ground with switchable director and reflector," IEEE Antennas Wireless Propag. Lett., vol. 16, pp. 24-28, 2017.

[21] W.-Q. Deng, X.-S. Yang, C.-S. Shen, J. P. Zhao, and B.-Z. Wang, “A dual-polarized pattern reconfigurable Yagi patch antenna for microbase stations," IEEE Trans. Antennas Propag., vol. 65, no. 10, pp. 5095-5102, Oct. 2017.

[22] M.-C. Tang, B. Zhou, and R. W. Ziolkowski, "Low-profile, electrically small, Huygens source antenna with pattern-reconfigurability that covers the entire azimuthal plane," IEEE Trans. Antennas Propag., vol. 65, no. 3, pp. 1063-1072, Mar. 2017.

[23] Y. Chen, and C.-F. Wang, "Electrically small UAV antenna design using characteristic modes," IEEE Trans. Antennas Propag., vol. 62, no. 2, pp. 535-545, Feb. 2014.

[24] S. Lim and H. Ling, "Design of electrically small, pattern reconfigurable Yagi antenna," Electron. Lett., vol. 43, no. 24, 2007.

[25] S. Hong, S. H. Kang, Y. Kim, and C. W. Jung, "Transparent and flexible antenna for wearable glasses applications," IEEE Trans. Antennas Propag., vol. 64, no. 7, pp. 2797-2804, Jul. 2016.

[26] B. D. Braaten, S. Roy, S. Nariyal, M. A. Aziz, N. F. Chamberlain, I. Irfanullah, M. T. Reich, and D. E. Anagnostou, "A self-adapting flexible (SELFLEX) antenna array for changing conformal surface applications," IEEE Trans. Antennas Propag., pp. 655-665, vol. 61 no. 2, Feb. 2013.

[27] M.-C. Tang, H. Wang, and R. W. Ziolkowski, "Design and testing of simple, electrically small, low-profile, Huygens source antennas with broad-side radiation performance,"' IEEE Trans. Antennas Propag., vol. 64, no. 11, pp. 4607-4617, Nov. 2016.

[28] M.-C. Tang and R. W. Ziolkowski, "Two-element Egyptian axe dipole arrays emphasising their wideband and end-fire radiation performance," IET Microw. Antennas Propag., vol. 9, no. 13, pp. 1363-1370, Oct. 2015.

[29] ANSYS/ANSOFT. (2012). High Frequency Structure Simulator (HFSS), Version 13.0. [Online]. Available: http://www.ansoft.com.

[30] C. A. Balanis, Antenna Theory, 4th ed. Hoboken, NJ: John Wiley \&Sons, 2016.

[31] R. W. Ziolkowski, P. Jin, and C.-C. Lin, "Metamaterial-inspired engineering of antennas," Proc. IEEE, vol. 99, pp. 1720-1731, Oct. 2011.

[32] MACOM. (2017). Products: MA4GP907. [Online]. Available: http://cdn.macom.com/datasheets/MA4GP907.pdf.

[33] C. Icheln, J. Krogerus, and P. Vainikainen, "Use of balun chokes in small-antenna radiation measurements," IEEE Trans. Instrum. Meas., vol. 53, no. 2, pp. 498-506, Apr. 2004

[34] StarLab Version D User Guide 1.0, Reference: TD. 224.1.08. SATF. A, SATIMO Corp., France, 2008.

[35] M.-C. Tang, B. Y. Zhou, and R. W. Ziolkowski, "Flexible uniplanar electrically small directive antenna empowered by a modified CPW-feed," IEEE Antennas Wireless Propag. Lett., vol. 15, pp. 914-917, 2016.

[36] A. Haskou, A. Sharaiha, and S. Collardey, "Design of small parasitic loaded superdirective end-fire antenna arrays," IEEE Trans. Antennas Propag., vol. 63, no. 12, pp. 5456-5464, Dec. 2015.

[37] W. T. Khan, A. C. Ulusoy, G. Dufour, M. Kaynak, B. Tillack, J. D. Cressler, and J. Papapolymerou, "A D-band micromachined end-fire antenna in 130-nm SiGe BiCMOS technology," IEEE Trans. Antennas Propag., vol. 63, no. 6, pp. 2449-2459, Jun. 2015.

[38] W. T. Khan, A. L. V. López, A. C. Ulusoy, and J. Papapolymerou, "Packaging a W-band integrated module with an optimized flip-chip interconnect on an organic substrate," IEEE Trans. Microw. Theory Techn., vol. 62, no. 1, pp. 64-72, Jan. 2014.

[39] M.-C. Tang, T. Shi, and R. W. Ziolkowski, "Flexible efficient quasi-Yagi printed uniplanar antenna," IEEE Trans. Antennas Propag., vol. 63, no. 12, pp. 5343-5350, Dec. 2015.

[40] A. D. Yaghjian, T. H. O'Donnell, E. E. Altshuler, and S. R. Best, "Electrically small supergain end-fire arrays," Radio Sci., vol. 43, no. 3, pp. 1-13, 2008. 